\title{
Giant Gallstone: A Rare Indication of Open Gholegystectomy
}

\author{
Satish Dalal, Pankaj, Sandeep Bhoriwal, Ramesh Kumar, Sujata \\ From the Department of General Surgery, Pt. B.D.S. PGIMS, \\ Rohtak-124001, Haryana.
}

Abstract:

Gallstones are the most common biliary pathology. Gallstone disease is more common in western world than Asia with females being more commonly affected than men. Gallstones can be as small as sand or as large as a golf ball. Gallstones with a diameter of over five $\mathrm{cm}$ are rare. We present a case of gallstone of size $74 \times 54 \mathrm{~mm}$ which weighed 72 grams.

Key words: Gallstones, Cholelithiasis, Cholecystitis, Cholecystectomy, Stone, Metronidazole.

\section{Introduction}

Gallstones are the most common biliary pathology. The gall bladder may contain a single large stone or many smaller ones. The aetiology of gallstone is probably a combination of defect in lipid metabolism and super-saturation of bile contents, especially cholesterol. About $10 \%$ of population have gall stones, but the vast majority experience no symptoms and needs no treatment. Laparoscopic cholecystectomy is the gold standard treatment for gall stone disease but very large gall stone may require open cholecystectomy. We encountered a rare case of giant gallstone which was successfully managed by open cholecystectomy.

\section{Case Report}

A 38 year female with type 2 diabetes was admitted to emergency department with complaints of right hypochondric pain. She gave history of intermittent right upper quadrant pain after meals for the last six months. Examination revealed, abdominal tenderness at right upper quadrant and epigastrium. Patient was afebrile and routine laboratory investigations were normal except for mild leucocytosis. Other blood tests (blood urea, sugar, electrolytes, serum bilirubin, serum amylase, SGOT, SGPT and serum alkaline phosphatase) were normal. Abdomen ultrasonography revealed a thickened gall bladder wall and a single giant pear shaped gallstone of size approximately $78 \times 59 \mathrm{~mm}$. No abnormality was detected in biliary tract, and there was no intra-abdominal collection of fluid. After diagnosis of acute cholecystitis, antibiotics ceftriaxone, amikacin, metrogyl, bowel rest, intravenous fluids and proton pump inhibitors were given to the patient. Patient showed significant improvement in her symptoms and was discharged in stable condition.

Corresponding Author: Dr. Pankai

Email: pritisaini2013@yahoo.in

Received: December 17, 2013 | Accepted: January 8, 2014 | Published Online: January 15, 2014

This is an Open Access article distributed under the terms of the Creative Commons Attribution License (creativecommons.org/licenses/by/3.0)

Conflict of interest: None declared | Source of funding: Nil | DOl: http://dx.doi.org/10.17659/01.2014.0005 
After one month elective open cholecystectomy was done through right subcostal incision. On surgical exploration, the stone filled the gall bladder and was difficult to manipulate. First a fundal incision was given to remove the stone from gall bladder and a standard cholecystectomy was performed. Thereafter, we found a single pear shaped gall stone of size $74 \times 54 \mathrm{~mm}$ [Fig.1]. Histopathological examination revealed chronic cholecystitis with cholelithiasis. On the third post-operative day, the patient was discharged from the hospital in stable condition. The stone was predominantly white in colour, containing black and dark green pigmented areas, with a smooth surface and semihard in consistency.

\section{Discussion}

Gallstone disease is a very common clinical condition. Gallstone disease is more common in western world than Asia with females being more commonly affected than men [1]. The aetiology of gallstone is probably a combination of defect in lipid metabolism and super-saturation of bile contents, especially cholesterol. It is rare in the first two decades. Incidence gradually increases after 21 years and it reaches the peak in the fifth and sixth decades. Women are affected more often than men in the ratio of $4: 1$. It is said that gallstone is more common in fat, fertile, forty and females. This gender difference may be due to the fact that estrogen increases the concentration of cholesterol in bile, leading to an excess of cholesterol and slowed gall bladder movements. Diabetic patients have a propensity for obesity, hypertriglyceridemia and gall bladder hypomotility. Therefore, it has been difficult to prove that diabetes is an independent risk factor for gall stone formation. However, some studies have shown an increased prevalence of diabetes in patients with gallstones [2].

Gallstone disease remains one of the most common medical problems leading to surgical intervention.

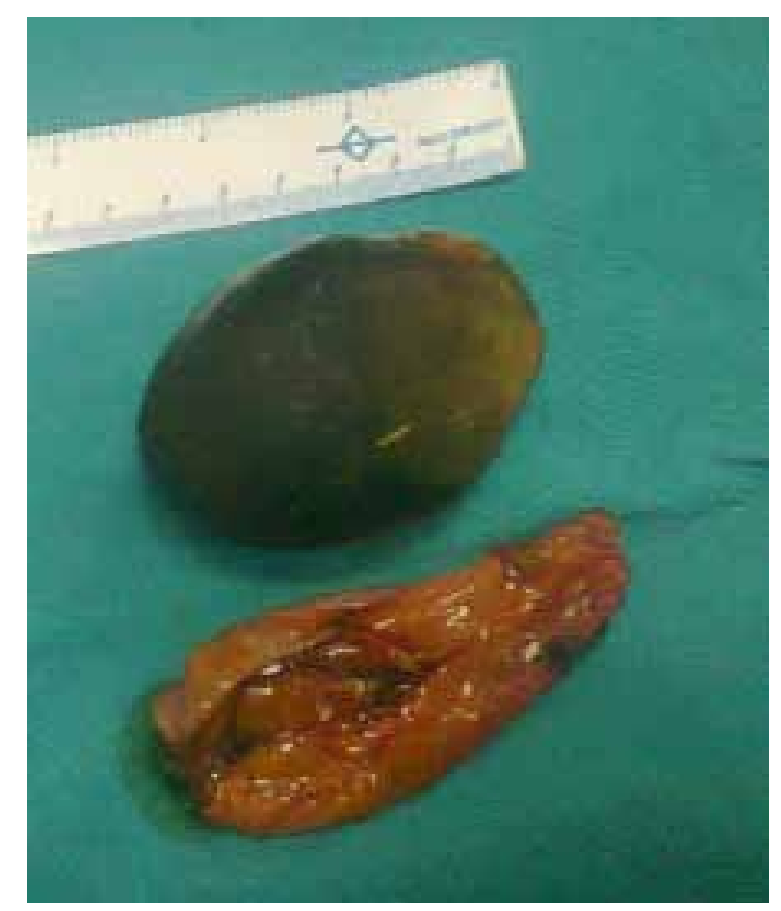

Fig.1: Peroperative photograph showing a giant gallstone

Some patients may remain asymptomatic, while some progress to a symptomatic stage [3]. The gall bladder may contain a single large stone or many smaller ones. Gallstones can be as small as sand or as large as a golf ball. But gallstones with a diameter of over five $\mathrm{cm}$ are very rare. Giant gall bladder stones, one measuring four inch in circumference and another six and a half inch long and six inch thick have been reported $[4,5]$. We present a case of gallstone of size $74 \times 54 \mathrm{~mm}$ and weighed 72 grams and was composed of bilirubin and cholesterol with traces of organic matter.

Laparoscopic cholecystectomy is the gold standard treatment for symptomatic gall stones presently. But laparoscopic cholecystectomy can be difficult procedure in presence of giant gall stone like the one we encountered. Large gallstones would result in more severe inflammation and thickening of the gallbladder wall. And the large gallstone would make it difficult to grasp the gallbladder with the 
laparoscopic instruments and expose the anatomy of Calots triangle. Difficulty will also occur in the retrieval of such a large gallstone. Because of these reasons, open cholecystectomy is the preferred procedure in such cases.

\section{Conclusion}

Giant gallstone of size more than $5 \mathrm{~cm}$ in diameter is very rare, we present a case of giant gallstone measuring $74 \times 54 \mathrm{~mm}$. Open cholecystectomy is still the procedure of choice in such cases instead of laparoscopic cholecystectomy.

\section{References}

1. Lammert F, Saverbruch T. Mechanisms of disease: the genetic epidemiology of gall bladder stones. Nat Clin Pract Gastroenterol Hepatol. 2005;2(9):423-433.

2. Jorgensen T. Gall stones in a Danish population. Relation to weight, physical activity, smoking, coffee consumption and diabetes mellitus. Gut.1989;30:528-534.

3. Ahrendt SA, Pitt HA. Biliary tract. In: Townsend MC (ed). Sabiston textbook of surgery. Philadelphia: Elsevier-Saunders; 2004, $1597-$ 1641.

4. Lichtman, SS. Diseases of the liver, Gall Bladder and Bile duct. $3^{\text {rd }}$ Edition. Lea and Febiger; Philadelphia; 1953, pp.1198.

5. Bockus, HL. Gastro-Enterology. Vol.3, $2^{\text {nd }}$ Edition, W.B. Saunders Company: Philadelphia, London and Toronto; 1965, pp.954. 